\title{
Педагогика
}

\author{
УДК 37.025
}

\section{М.В. Иванов}

\section{ТЕОРИЯ ДИДАКТИКИ И ПРАКТИКА ОБУЧЕНИЯ В КОНТЕКСТЕ ПОЗИТИВНОГО И НЕГАТИВНОГО ВЫБОРА СОЗНАНИЯ}

Статья посвящена механизму позитивного и негативного выбора сознания, получившего свое обоснование в теории В.М. Аллахвердова. Сознание появляется как конструктивная реакция психики на неопределенность состояния, в котором невозможно использовать тот или иной автоматизм для успешного регулирования поведения. Психика человека сразу после его рождения получает огромную информацию и тщательно фиксирует ее. На базовом (неосознанном уровне) хранится весь личный «архив» индивидуального опыта в максимальной полноте. На поверхностном (осознанном) уровне поток сознания течет непрерывно и обеспечивает прием высших, рациональных решений. Но на уровень осознанности базовое сознание процедурой ограничения допускает те образы и стратегии, которые нужны для разрешения актуальных и не до конца понятных проблем. Пока варианты неосознанных (негативно выбранных) идей находятся в бессознательном, они не изменяются, не модифицируются и составляют устойчивую основу для осознанного поиска. Применение таких теоретических установок помогает переоценить устоявшиеся педагогические воззрения. У педагога появляются важные дидактические функции. Когда ученик узнает новый научный термин, то автоматически может неточно связать его с имеющимся интеллектуальным опытом и лишь в диалоге с учителем переходит от ошибочных утверждений к истинным. Преподаватель помогает преодолеть разнообразные негативные выборы и приблизиться к успешному позитивному выбору. Педагог выступает и как побудитель к творчеству, помогая ученику при решении нестандартных задач активизировать внутренние ресурсы по устранению барьера в бессознательном. Инсайт снимает блокировку с имевшего уже ранее, но негативно выбранного варианта. Главная функция педагога как воспитателя состоит в том, чтобы помочь обучающемуся достичь позитивного личностного самоопределения, которое прочно сохраняет и активность поиска, и критичность самооценки.

Ключевые слова: сознание, базовый и поверхностный уровни, позитивный и негативный выбор, блокировка, творчество, инсайт, личностное самоопределение.

DOI: 10.35634/2412-9550-2020-30-2-189-194

Дидактика и психология познания представляют две смежные области человекознания, влияющие на развитие теории и практики передачи опыта между людьми. Функционирование институтов образования ориентировано на применение в педагогической деятельности концептуальных моделей, синтезирующих дидактические и собственно психологические идеи. В настоящее время особенно значимым становится исследование познания в ходе обучения как процесса творческого, продуктивного, активного. Но теоретическое осознание инсайта сталкивается с немалыми трудностями, а методы повышения креативности учащихся представляют собой в основном полезные, но разрозненные рекомендации. И продвижение к целостному представлению о психологии и педагогике творчества может получить дополнительный импульс при использовании концепции позитивного и негативного выбора сознания.

Установление механизма позитивного и негативного выбора сознания произошло в рамках когнитивной психологической теории, названной психологикой, которая получила свое обоснование в трудах Виктора Михайловича Аллахвердова [1;2] и его школы [10; 11]. Следует кратко изложить основные идеи этого перспективного направления в психологии, которое, на первый взгляд, поражает парадоксальностью подхода к привычным проблемам психической жизни. (Подробный анализ концепции психологики см. в [7; 8]). Физиологические механизмы работают отлажено и бесперебойно, но в режиме автоматизмов; поэтому они не способны функционировать в ситуации неопределенности. Сознание появляется как конструктивная и креативная реакция психики, когда невозможно использовать тот или иной рефлекторный способ действия для успешного регулирования жизнедеятельности. При возникновении принципиально новой проблемы неясно, какая из возможных программ регулирования будет адекватной. Тогда включается протосознание - механизм, который осуществляет случайный выбор одной из них, но придает ему статус обязательного ответа на данную 
ситуацию. Когда выбор сделан, сознание не может отключиться, так как только оно в состоянии обеспечить последовательность поведения, регулируя его и контролируя последствия принятого решения. На базовом (не осознанном) уровне весь личный «архив» хранится в максимальной полноте. На поверхностном (осознанном) уровне поток сознания течет непрерывно (уж точно в периоды бодрствования) и обеспечивает прием высших, рациональных решений. Всё, что подтверждает сформировавшуюся установку (позитивный выбор), принимается; всё, что не подтверждает (негативный выбор), - сначала игнорируется или перетолковывается во имя сохранения сделанного выбора. Гештальтисты открыли закон последействия фигуры. То, что исходно воспринимается фигурой на фоне, будет и при последующих предъявлениях опознаваться как фигура. Психологика обосновывает более широкий взгляд на проблему: в восприятии закрепляется не только фигура, но и фон; тем самым проявляется закон последействия фигуры и фона. Выбрав фигуру, сознание не игнорирует и фон, его учитывает, хранит и лишь блокирует его доступ в контролируемую обработку поступающей информации. Фон не уходит в небытие, а составляет фонд учтенного, но не представленного в непосредственном переживании и обдумывании богатого психического опыта - опыта взаимодействия с внешним миром и самопознания. В совокупности осознанные и блокированные идеи и образы создают огромный запас информации, дающий возможность человеку опираться на космос личного опыта. Выбор фиксирует не только принятие, но и отвержение, остается найти к нему доступ.

Позитивный выбор не означает и неразрушимого конструирования во имя стопроцентного подтверждения принятой гипотезы. Неизменная и постоянно полностью подтверждаемая информация достаточно быстро становится ожидаемой и даже вопреки желанию испытуемых ускользает из их поверхностного слоя сознания (как тиканье часов в привычных условиях). Из поверхностного сознания в базовое удаляется либо негативно выбранная гипотеза (там она блокируется), либо полностью подтвержденная (при необходимости легко восстанавливается). На осознанном же уровне сохраняется динамический процесс обработки не полностью подтвержденной или представленной в каком-либо изменяющемся виде информации (с помощью движения глаз, смены фокуса внимания, переинтерпретации и т. д.). Философ А.С. Кармин так писал о предложенной теории: «Если результаты идущих в сфере бессознательного информационных процессов в одних случаях осознаются, а в других не доходят до сознания, то приходится предполагать, что существует некий «когнитивный механизм»...Этот механизм, впервые обнаруженный В.М. Аллахвердовым на основании полученных им экспериментальных данных, останавливает перед порогом сознания одни информационные процессы (негативный выбор) и пропускает в сознание продукты других процессов (позитивный выбор)» [9. С. 390].

Применение теоретических установок психологики помогает переоценить многие устоявшиеся педагогические воззрения. Европейское Просвещение в XVIII веке провозгласило всемогущество разума, который опирается на логику, эрудицию и ориентирует на волевые усилия: всё делать осознанно, внимательно, предельно сосредоточенно, в соответствии с методическими (т. е. фиксированными в точных формулировках) правилами, Идеализировалась всемогущая власть «сознания». В педагогике стало предполагаться, что «правильная» психическая жизнь сводится к процессам саморегуляции на осознанном уровне. Открывался путь к бюрократизации учебного процесса - жестко формализованного и репродуктивного. Поэтому сложилось превратное представление о процессе передачи знания. Ум ученика - это незаполненный сосуд, в который учитель вкладывает шары нужных истин. Чем дольше протекает обучение, тем выше становится уровень заполненности сосуда познания, тем богаче тезаурус - умственное сокровище.

Теория позитивного и негативного выбора располагает к другому пониманию дидактики. Психика человека сразу после его рождения получает огромную информацию и тщательно фиксирует ее. Но на уровень осознанности базовое сознание процедурой ограничения допускает те образы и стратегии, которые нужны для разрешения насущных, актуальных и не до конца понятных проблем, разрешение которых направлено на постижение регулярностей, обеспечивающих улучшение внешней и внутренней ситуации. Сознание ограничивает само себя, имея обширный физиологический запас фиксированного опыта. Отвержение - столь же конструктивный процесс, что и принятие. Пока эти варианты неосознанных идей находятся в бессознательном, они не изменяются, не модифицируются и составляют устойчивую основу для осознанного поиска. Если омонимичное слово воспринято с одним значением, то остальные - отвергнутые - плотной стеной окружили «фаворита» позитивного выбора и не позволят ему легко поменять обличье. 
У педагога имеются две важные дидактические функции: 1) ознакомление учащихся с новым материалом по предмету и помощь в его осмыслении на современном интеллектуальном уровне, 2) развитие их способности самостоятельно порождать новое знание. Первая из них говорит о неустранимости учителя из учебного процесса. Рассуждения о том, что учитель просто помогает ученикам развивать их интересы, выглядит наивным и оказывается коварным. Содержание школьных и вузовских программ задано молодому поколению извне - со стороны общества. Нелепо полагаться на «естественный ход» интеллектуального созревания младых умов. Как сказал А.Н. Уайтхед, «в конце концов ребенок является наследником многовековой цивилизации, и глупо позволять ему блуждать по интеллектуальному лабиринту человека эпохи оледенения» [6. С. 146]. На каждом предмете учитель вводит новый для учащегося тип языка - научный. И дидактическая цель состоит в том, чтобы научить питомцев строить рассуждения на нем и решать задачи с его помощью. Здесь возникают сложные проблемы. Язык науки не может быть усвоен путем буквального заучивания и простого воспроизведения. Он ведь усваивается на основе обыденного, разговорного языка. Привычное чтение учебника и слушание речи учителя никак не гарантирует осознание именно научного языка, направленного на установление связи абстрактных познавательных моделей с реальным - и весьма ограниченным опытом ученика. Парадокс любого текста состоит в том, что тот несет более богатое содержание, чем дает сумма значений содержащихся в нем слов. Любые формы фиксации изучаемого материала относятся к зоне выраженности - эксплицитности. Но она может адекватно осознаваться только при соответствующих имплицитных установках, т. е. в понимании сказанного на фоне несказанного, но ясно подразумеваемого - нужного контекста.

Когда ученик узнает новый научный термин, то автоматически связывает его с имеющимся интеллектуальным опытом и устанавливает границы с «нет» очень приблизительно. А этих «нет» во много раз больше, чем принятого «да». Все оговорки (А - это не В, не С и т.д.) не предусмотришь. Хуже того, если даже сделать такой грузный реестр, то ученик просто ничего не поймет из-за обилия уточнений. Остается только один путь. Когда ученик узнает новый научный термин, то автоматически может неточно связать его с имеющимся интеллектуальным опытом и лишь в диалоге с учителем переходит от ошибочных утверждений к истинным. Преподаватель помогает преодолеть разнообразные негативные выборы и приблизиться к успешному позитивному выбору. Известно, что когда ребенком «на первом этапе обучения строятся правила обращения со сложной системой...их применение в определенных случаях ведет к ошибкам» [6. С. 132]. Пытаясь решить предложенную задачу, «одни дети принимают во внимание то, что говорит им экспериментатор, другие замещают его вопрос своим собственным, «более естественным» [6. С. 112]. При решении логических задач, предложенных М. Хелл, «типы ошибок были связаны с полным игнорированием одной из посылок, с выделением дополнительной, а также с переформулированием посылки или вывода, менявшим их значение. Что здесь особенно удивительно, так это то, что испытуемыми были студенты, закончившие университет» [6. С. 94]. Профессиональное чутье учителя и есть тот уникальный профессиональный опыт, который применяется без промедления как экспертная способность.

«Умения ребенка должны оцениваться весьма внимательно и точно, с пониманием его уровня уверенности в себе и его активности, а реакция на его ошибки должна быть формой помощи», справедливо утверждает Маргарет Доналдсон. И тут же добавляет: «А общей формулы, гарантирующей успех, не существует». Поэтому Мэрион Бланк в книге «Обучение дошкольников учиться» (1973) помощь учителя детям в исправлении ошибок относит к области искусства [6. С. 141]. Преподаватель помогает преодолеть разнообразные негативные выборы и приблизиться к успешному позитивному выбору.

Учитель выступает как побудитель к творчеству. Психологика исходит из представления о сознании как об активном механизме, направленном на поиск успешного выбора в ситуации неопределенности. При росте нетривиальности задания фиксированные умственные привычки не срабатывают. Требуется диалог базового и поверхностного сознания как независимых систем. Поверхностное сознание обрабатывает информацию на основе методов и идей позитивного выбора и в решающем большинстве случаев успешно справляется с разнообразием задач в границах привычного смыслового поля. При росте неадекватности применяемых осознанных методов возникает необходимость обратиться к базовому сознанию, в котором находится возможный успешный вариант, ставший объектом негативного выбора. 
Обычная трактовка появления новой мысли связана либо с простым перебором осознанных идей в поисках подходящего сочетания (позитивистская модель), либо с усвоением нового опыта, который содержит необходимую подсказку, как разрешить нетривиальную проблему. Гештальтисты выдвинули глубокую идею инсайта (озарения), позволяющего сменить один образ, оказавшийся ущербным, на другой - «хороший», всё расставляющий по своим местам. Но неясно было, как выделяемая на «фоне» «фигура» вдруг преображается в другую. Психологика дает ответ: инсайт снимает блокировку с ранее негативно выбранного варианта, который можно называть образом, гештальтом, фигурой, идеей, т.е. структурированным ментальным элементом, всплывающем в поверхностном сознании. Такое объяснение делает неуместным представление об обучении как о вкладывании шаров мудрости в пустой сосуд. Ответ на трудный вопрос уже имеется в сознании ученика, но блокирован. И роль учителя состоит в помощи по устранению барьера в бессознательном ученика. «Творчество имеет место только тогда, когда новое достигается самостоятельно, а не путем подражания, копирования его, заимствования способа его получения. Субъект должен «дойти» до него своим умом» [6. С. 76]. Учитель способствует освобождению мысли подопечного. Океан бессознательного - это необъятный резерв фактов и идей, и часть из них может попасть в поток сознания, когда открываются шлюзы плотины, созданной неудачным негативным выбором. В общем плане активизация творческого поиска осуществляется так: после постановки перед учеником трудной задачи педагог предлагает обдумать другую, не связанную с ней проблему, у которой имеется легкое решение. Но в этом простом задании есть скрытая подсказка для преодоления исходного затруднения. И тогда правильное понимание осознается. И всё же следует обратить внимание на то, что неправильно выбранная осознанная стратегия стремится и дальше воспроизводиться, а с каждым повтором закрепляется, усиливая блокировку замурованного в бессознательном эффективного подхода. Повторами инсайта не дождешься. Самым же важным в таком подходе психологики мне представляется то, что у человека можно выработать уверенность в своих исключительно богатых потенциях, в способности раскрыть изобилие своего внутреннего мира, в опоре на свои силы (а не на вечную помощь извне), в успешности взаимодействия поверхностного и базисного уровней сознания для улучшения своего внутреннего состояния и внешних условий жизни.

Математики - поклонники наиболее последовательно, наиболее логично выстроенных моделей обоснования. Но и они признают, что любая кодовая система предполагает неизбежность такого соединения знаков (построения «высказывания» при правильном употреблении правил сочетания), когда утверждение не поддается оценке, истинное оно или ложное. Это доказывает теорема Геделя [14]. Возникшую неопределенность можно преодолеть, если раздвинуть границы привычного языка, создать метаязык. Но тот встретится с трудностями более высокого уровня. Таков путь сознания: вечно открывать и сталкиваться с парадоксами нового знания. Случайно предпочтенный выбор (позитивный) определяет последующее поведение. А если предпочтен не лучший вариант? Он ведь получил привилегию реализовываться, потеснив более успешный поход, который стал жертвой негативного выбора. По закону последействия фигуры и фона первый будет последовательно избираться сознанием, а второй столь же последовательно отвергаться. На жизненном пути, особенно в ранние годы слишком много неопределенных ситуаций, и успешный случайный выбор служит источником созревания таланта, а неэффективный - создает барьеры для нормального развития (душевные травмы, фобии, неуверенность в себе, затрудненное и фрагментарное понимание учебной информации, которое М. Вертгеймер назвал «слепым» [4. С. 301]). И учитель должен уметь снимать многие барьеры, которые ученики получили в результате неудачного негативного выбора. Но не нужно забывать и того, что в дальнейшем проявивший талант человек получает поддержку талантливых учителей, которые поддерживают стремление ученика к преодолению барьеров. Известно, что маленький Моцарт брал уроки у сына Иоганна Себастьяна Баха.

Психологика изменяет взгляд и на теорию воспитания. Первоначально удержание в сознании тождественности своей личности достигается просто практикой исполнения роли в схожих, но слегка изменяющихся обстоятельствах (привычном вибрировании событий, отождествленных с помощью механизма константности). Если же внешняя запрограммированность поведения становится избыточной, сознание может меркнуть, и его восстановление выражается в поиске человеком циклично изменяющейся, но типологически однородной информации (погружение в «компьютерную жизнь»: поверхностную болтовню или примитивные игры; прослушивание ритмически и мелодийно упрощенной музыки). «Набивать руку» на заполнении опросников ОГЭ/ЕГЭ - это усердно способствовать 
потере интереса к предмету. Положительный же полюс роста самосознания определяется его творческой природой. Личность творит себя, используя социальный опыт взаимодействия, постигая всё новые языки познания, но органически сочетая новое знание с уникальным биографическим опытом. Лозунг древних греков: «Познай самого себя!» - обозначил этот путь. И в таком случае главная функция педагога как воспитателя состоит в том, чтобы помочь питомцу достичь позитивного личностного самоопределения, которое прочно сохраняет и активность поиска, и критичность самооценки.

В педагогике проблема «извлечения» нового знания из имеющегося духовного опыта рационально представлена уже в спорах Сократа, который доказывал, что истину надо добывать, что она не лежит на поверхности. Сократ разделил неведение и незнание. Первое связано просто с непредставленностью в сознании проблемы как таковой, второе - с осознанием ее, но пониманием ее нерешенности в данное время. Из интеллектуального оформителя общепринятых идей и правил сознание превращалось в инструмент решения все новых проблем и парадоксов. Догматический акцент уступал место творческому. Метод Сократа ориентировал добывать истину в межличностном контакте умных собеседников, когда ни одному из них она заранее не известна.

Теория позитивного и негативного выбора объясняет своеобразие каждой личности, ибо исходит из уникального жизненного сюжета, который создается последовательностью выборов человека на пути решения проблем, порожденных сочетанием конкретных состояний психики (внутренних условий) и конкретных же житейских ситуаций (внешних условий). Преодоление раздробленности индивидов обеспечивается их стремлением к согласию через общение и освоение культурных норм и ценностей. Но каждый человек должен это сделать сам, преодолев неэффективные негативные выборы и приняв успешные позитивные. Педагогика же помогает осуществить такую деятельность, соединяя выработку гибких стратегий обучения и воспитания с подготовкой талантливых учителей, способных поддержать учеников в их неповторимом личном поиске пути к освоению выработанных культурой социальных, интеллектуальных, нравственных ценностей. Искусство учителя состоит во многом из понимания того, какие конкретные когнитивные барьеры следует преодолеть именно этому ученику и как их преодолевать. Это есть творческий процесс, объединяющий их в совместном труде. Активные методы обучения (метод Шаталова, коллективного обучения, сменных групп, проблемно-проектного обучения, тренинговый $[3 ; 13 ; 15 ; 16])$ имеют диалоговую природу и стимулируют свободную форму совместного поиска лучшего решения, способствуя снятию нежелательных, консервативных барьеров. А информационная сокровищница каждого человека, накопленная благодаря действию механизмов позитивного и негативного выбора, столь велика, что представляет внутренний, психический космос.

В заключение можно сказать, что концепция позитивного и негативного выбора позволяет значительно расширить представление о масштабе субъективного опыта каждой личности. У педагогов должна превалировать активизация персонального опыта учащегося с опорой на снятие индивидуальных барьеров, образованных негативным выбором, и переводом на осознанный уровень уже имеющихся в бессознательном вариантов эффективного позитивного выбора. Этот процесс не может быть полностью формализован и требует искусства учителя, что делает обучение уникальной двунаправленной креативной деятельностью (от педагога к учащемуся и обратно). Теория психологики создает возможности для эвристических поисков взаимодействия учителя и ученика в освоении интеллектуального наследия цивилизации.

\section{СПИСОК ЛИТЕРАТУРЫ}

1. Аллахвердов В.М. Психика и сознание в логике познания // Вестник Санкт-Петербургского университета. Серия 16. Психология. Педагогика. 2016. № 1. С. 35-46.

2. Аллахвердов В.М. Размышление о науке психологии с восклицательным знаком. СПб.: Формат. 2009. 264 с.

3. Баранов А.А., Шарафутдинов Р.Н. Формирование и развитие экологической компетенции у будущего учителя технологии на основе проблемно-проектного обучения // Вестник Удмуртского университета. Сер. Философия. Психология. Педагогика. 2017. Т. 27, вып. 4. С. 483-490.

4. Вертгеймер М.. Продуктивное мышление. М.: Прогресс. 1987. 336 с.

5. Гусева Е.А. Психологические подходы к изучению творчества // Карминские чтения. Актуальные проблемы философии, культурологии, психологии, конфликтологии, права и образования: материалы IV Национальной с международным участием науч.-практ. конф. СПб.: ФГБОУ ВО ПГУПС, 2019. С. 72-80.

6. Доналдсон М. Мыслительная деятельность детей. М.: Педагогика. 1985. 191 с. 
7. Иванов М.В., Ситников В.Л. Сознание ученого в океане бессознательного (к 70-летию Виктора Михайловича Аллахвердова) // Российский гуманитарный журнал. 2016. Т. 5. С. 646-656.

8. Иванов М.В. Образ и логика психологики // Когнитивная логика сознательного и бессознательного. СПб.: Изд-во СПбГУ, 2006. С. 301-324.

9. Кармин А.С. Интуиция. Философские концепции и научное исследование. СПб.: Наука, 2011. 902 с.

10. Когнитивная психология сознания. СПб.: ЛЕМА, 2011. 194 с.

11. Когнитивная логика сознательного и бессознательного. СПб.: Изд. СПбГУ. 2006. 352 с.

12. Колеченко А.К. Энциклопедия педагогических технологий. СПб.: Каро. 2008. 268 с.

13. Педагогический поиск. М.: Педагогика. 1987. 544 с.

14. Пиньейро Г.Э. У интуиции есть своя логика. Гёдель. Теоремы о неполноте // Наука. Величайшие теории. М.: Де Агостини, 2015. Вып. 17. 168 с.

15. Рыжов В. Методическая система В.Ф. Шаталова. Изд. LAP, 2012. 128 с.

16. Шаталов В.Ф. Эксперимент продолжается. Донецк: Сталкер. 1998. 336 с.

Поступила в редакцию 25.03.2020

Иванов Михаил Васильевич, доктор филологических наук, профессор, профессор кафедры «Прикладная психология», действительный член Российской академии транспорта Петербургский государственный университет путей сообщения императора Александра I 190031, Россия, г. Санкт-Петербург, Московский проспект, 9

E-mail: mvifp@mail.ru

\title{
M.V. Ivanov \\ DIDACTICS THEORY AND LEARNING PRACTICES IN THE CONTEXT OF POSITIVE AND NEGATIVE CHOICE OF CONSCIOUSNESS
}

\author{
DOI: $10.35634 / 2412-9550-2020-30-2-189-194$
}

The article is devoted to the mechanism of positive and negative choice of consciousness, which received its justification in the theory of V.M. Allakhverdov. Consciousness appears as a constructive reaction of the psyche to the uncertainty of a state in which it is impossible to use one or another automatism to successfully regulate behavior. The human psyche immediately after its birth receives a huge amount of information and carefully records it. At the basic (not conscious) level, the entire personal "archive" of individual experience is stored in the maximum completeness. At the surface (conscious) level, the stream of consciousness flows continuously and provides the reception of higher, rational decisions. But at the level of awareness, the basic consciousness without restriction allows for those images and strategies that are necessary for solving urgent and not fully understood problems. As long as variants of unconscious ideas remain in the unconscious, they do not change or modify and form a stable basis for conscious search. The use of such theoretical attitudes helps to re-evaluate many established pedagogical views. The teacher has important didactic functions. When a student learns a new scientific term, he can automatically connect it inaccurately with the existing intellectual experience and only in a dialogue with the teacher he goes from erroneous statements to true ones. The teacher helps one to overcome a variety of negative choices and get closer to a successful positive choice. The teacher also acts as a motivator for creativity, helping the student in solving non-standard tasks to activate internal resources to remove a barrier in the unconscious. Insight removes the block from the previously selected option that was negatively selected. The main function of the teacher as a caregiver is to help the student in achieving a positive personal self-determination, which firmly preserves both the search activity and the critical self-esteem.

Keywords: consciousness, basic and surface levels, positive and negative choices, blocking, creativity, insight, personal self-determination.

Ivanov M.V., Doctor of Philology, Professor, Professor at Department of Applied psychology, full Member of the Russian Academy of transport

St. Petersburg State University of Transport of the Emperor Alexander I

9, Moskovsky Prospekt, Saint Petersburg, Russia, 190031

E-mail: mvifp@mail.ru 